\title{
Percutaneous cholecystostomy in acute cholecystitis in a patient with stent restenosis suffering from recent non-ST myocardial infarction before coronary artery bypass grafting
}

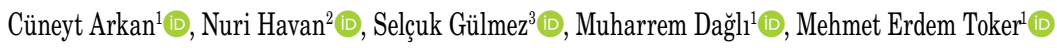 \\ ${ }^{1}$ Department of Cardiovascular Surgery, Kartal Koşuyolu Yüksek İhtisas Training and Research Hospital, Istanbul, Turkey \\ ${ }^{2}$ Department of Radiology, Kartal Koşuyolu Yüksek İhtisas Training and Research Hospital, Istanbul, Turkey \\ ${ }^{3}$ Department of Gastroenterology Surgery, Kartal Koşuyolu Yüksek İhtisas Training and Research Hospital, Istanbul, Turkey
}

Received: March 26, 2018 Accepted: April 21, 2018 Published online: April 24, 2019

\begin{abstract}
It may be challenging to tailor the treatment of acute cholecystitis in patients undergoing coronary artery bypass grafting due to accompanying comorbid factors. A 62-year-old male patient was admitted to the cardiovascular surgery unit for elective coronary artery bypass grafting. He suffered from non-ST-elevation myocardial infarction a week ago. His medical history revealed insulin-dependent diabetes mellitus and severe chronic obstructive pulmonary disease and also percutaneous coronary interventions in the left anterior descending and circumflex arteries 18 month ago. A coronary artery bypass grafting operation was planned a week after his admission. However, before coronary artery bypass grafting, the patient suffered from abdominal pain, nausea, and vomiting and the diagnosis of acute cholecystitis was made by the gastroenterology department. Percutaneous cholecystostomy was applied under ultrasonographic guidance. After the procedure, the complaints of the patient improved dramatically. Twelve days after the procedure, coronary artery bypass grafting was performed without any perioperative complications. The patient was uneventfully discharged on postoperative Day 8. In conclusion, percutaneous cholecystostomy is an effective method to maintain clinical stability in patients with acute cholecystitis who are candidates for open heart surgery.
\end{abstract}

Keywords: Acute cholecystitis; comorbidities; coronary artery bypass grafting; percutaneous cholecystostomy.

Acute cholecystitis before an elective coronary artery bypass grafting (CABG) is an unusual condition in daily practice and a very limited number of cases has been reported in the literature. It may be challenging to tailor the treatment of acute cholecystitis in these patients. Simultaneous surgical intervention or a staged procedure in which cholecystectomy is performed first may increase early morbidity and mortality, particularly in the presence of other comorbidities.

Percutaneous cholecystostomy (PC) is a technique which consists of percutaneous catheter placement in the gallbladder lumen under the guidance of imaging modalities and has become an alternative to surgical cholecystectomy in recent years. ${ }^{[1]}$ It is also a well-accepted procedure for acute cholecystitis in high-risk patients. ${ }^{[2]}$

Herein, we report a case of acute cholecystitis in a patient suffering from recent non-ST elevation myocardial infarction (NSTEMI) before CABG.

\section{CASE REPORT}

A 62-year-old male patient was admitted to the cardiovascular surgery unit for an elective CABG. He suffered from NSTEMI a week ago. His medical history revealed insulin-dependent diabetes mellitus and severe chronic obstructive pulmonary disease (COPD) and he was using the bilevel positive airway pressure machine in daily life. Also, percutaneous coronary interventions in the left anterior descending $(\mathrm{LAD})$ and circumflex $(\mathrm{Cx})$ arteries were performed

Corresponding author: Mehmet Erdem Toker, MD. Kartal Koşuyolu Yüksek İhtisas Ĕgitim ve Araştırma Hastanesi Kalp ve Damar Cerrahisi Kliniği, 34865 Kartal, İstanbul, Turkey.

Tel: +90 505 - 2379824 e-mail: mertoker@yahoo.com

\section{Citation:}

Arkan C, Havan N, Gülmez S, Dağlı M, Toker ME. Percutaneous cholecystostomy in acute cholecystitis in a patient with stent restenosis suffering from recent non-ST myocardial infarction before coronary artery bypass grafting. Cardiovasc Surg Int 2018;5(2):27-29. 
18 month ago. Coronary angiography which was performed in an external center revealed $90 \%$ proximal LAD lesions and $70 \% \mathrm{Cx}$ obtuse margin $2\left(\mathrm{CxOM}_{2}\right)$ lesions and stent restenosis on both arteries. On echocardiography, left ventricle ejection fraction (LVEF) was $65 \%$ without any significant valvular problem. Carotid ultrasonography showed a left internal carotid artery stenosis of $50 \%$ and no intervention was considered. Pulmonary function test revealed a forced expiratory volume in one second $\left(\mathrm{FEV}_{1}\right)$ of $16 \%$ and $\mathrm{FEV}_{1} /$ forced vital capacity (FVC) of $50 \%$. The patient was scheduled for an elective CABG one week after his admission and a written informed consent was obtained.

Before CABG, the patient suffered from abdominal pain, nausea, and vomiting and a bedside consultation was performed by the gastroenterology department. He had pain with deep palpation in the right upper quadrant. Abdominal ultrasonography showed an increased diameter of the gallbladder with a minimal thickening. The lumen of the gallbladder had lots of millimetric gallstones and mud. C-reactive protein (CRP) level significantly increased from $0.9 \mathrm{mg} / \mathrm{dL}$ to $1.16 \mathrm{mg} / \mathrm{dL}, 18.6 \mathrm{mg} / \mathrm{dL}$, and $19.8 \mathrm{mg} / \mathrm{dL}$, respectively on consecutive alternate days. Other laboratory test results were as follows: alkaline phosphatase (ALP) $70 \mathrm{U} / \mathrm{L}$, aspartate aminotransferase (AST) $19 \mathrm{U} / \mathrm{L}$, alanine aminotransferase (ALT) $12 \mathrm{U} / \mathrm{L}$, gammaglutamyl-transferase (GGT) $12 \mathrm{U} / \mathrm{L}$, and amylase $86 \mathrm{U} / \mathrm{L}$. The complete blood count analysis showed an increasing tendency in the white blood cell (WBC) count from $8,700 / \mu \mathrm{L}$ to $10,900 / \mu \mathrm{L}$, and $11,400 / \mu \mathrm{L}$ on consecutive alternate days. Based on the laboratory and ultrasonographic findings, the patient was diagnosed with acute cholecystitis caused probably by a millimetric gallstone particle obstructing the ductus cysticus. Oral intake was not allowed and intravenous fluid replacement was applied. Antibiotherapy was initiated and the gastrointestinal system was given a rest for a few days.

Ultrasonography and laboratory studies were repeated every two- or three-days. Ultrasonography revealed an increased thickness of wall of the gallbladder. Also, the pericholecystic fluid was seen which was not observed previously. Considering whole these findings, progression of the acute cholecystitis was suspected. The gastroenterology department reevaluated the patient and surgery was considered initially. However, due to comorbidities of the patient, they decided not to operate the patient and referred the patient to the invasive radiology department for PC. A written informed consent was obtained from the patient.

Percutaneous cholecystostomy was applied under the guidance of ultrasonography. After the procedure, the complaints of the patient improved dramatically. During the procedure, $200 \mathrm{~mL}$ bile fluid was drained. In the following days, about 50 to $200 \mathrm{~mL}$ bile fluid was drained each day. The WBC count was in normal range. Abdominal ultrasonography revealed a decreased size of the gallbladder. The CRP levels dramatically decreased from $19.8 \mathrm{mg} / \mathrm{dL}, 4.9 \mathrm{mg} / \mathrm{dL}$, and $7.11 \mathrm{mg} / \mathrm{dL}$, respectively. The gastroenterology department suggested that CABG should be done, when the CRP became lower than $5 \mathrm{mg} / \mathrm{dL}$ and $\mathrm{WBC}$ count was in normal range.

After clinical stabilization, two vessels CABG were performed with saphenous veins for the LAD and $\mathrm{CxOM}_{2}$ arteries 12 days after $\mathrm{PC}$ intervention. Left internal mammary artery (LIMA) graft was not used due to decreased flow. There were no major perioperative complications. He was extubated on the postoperative first day. Blood gas analysis showed a partial pressure of carbon dioxide $\left(\mathrm{pCO}_{2}\right)$ level of 55 to $60 \mathrm{mmHg}$. Due to existing COPD, these levels were thought to be well-tolerated and it was the case in our patient. In the following days, the patient was transferred to the ward. The percutaneous gallbladder catheter was withdrawn on the postoperative sixth day. No complication was seen, and the patient was discharged with complete recovery on the postoperative eighth day.

\section{DISCUSSION}

Acute cholecystitis before elective CABG is unusual in clinical practice and is even extremely rare following open heart surgery. ${ }^{[3]}$ Several studies have attempted to investigate whether risk factors for coronary artery disease are also risk factors for gallbladder diseases. ${ }^{[4,5]}$ Association of myocardial infarction with gallbladder disease has been previously examined in an epidemiological study; ${ }^{[6]}$ however, it is still not possible to suggest an exact relationship between them.

Percutaneous cholecystostomy is a well-accepted procedure for acute cholecystitis in high-risk patients. ${ }^{[2]}$ It can be used effectively in high-risk patients with cardiac problems, including acute myocardial infarction and other comorbidities. ${ }^{[2,7]}$ 
In the present case, surgical cholecystectomy was not considered as an option due to NSTEMI and severe COPD. Therefore, the gallbladder was relieved by draining with PC. Following the intervention, the patient became stable based on clinical, ultrasonographic, and laboratory findings. Subsequently, an elective CABG was performed and the patient was discharged without any postoperative complication.

In conclusion, we believe that percutaneous cholecystostomy is an applicable and feasible method for acute cholecystitis in high-risk patients who are candidates for elective coronary artery bypass grafting.

\section{Declaration of conflicting interests}

The authors declared no conflicts of interest with respect to the authorship and/or publication of this article.

\section{Funding}

The authors received no financial support for the research and/or authorship of this article.

\section{REFERENCES}

1. Akhan O, Akinci D, Ozmen MN. Percutaneous cholecystostomy. Eur J Radiol 2002;43:229-36.

2. Davis CA, Landercasper J, Gundersen LH, Lambert PJ. Effective use of percutaneous cholecystostomy in high-risk surgical patients: techniques, tube management, and results. Arch Surg 1999;134:727-31.

3. Passage J, Joshi P, Mullany DV. Acute cholecystitis complicating cardiac surgery: case series involving more than 16,000 patients. Ann Thorac Surg 2007;83:1096-101.

4. Diehl AK, Haffner SM, Hazuda HP, Stern MP. Coronary riskfactors and clinicalgallbladder disease: an approach to the prevention of gallstones? Am J Public Health 1987;77:841-5.

5. Méndez-Sánchez N, Bahena-Aponte J, Chávez-Tapia NC, Motola-Kuba D, Sánchez-Lara K, Ponciano-Radríguez G, etal.Strongassociation betweengallstonesand cardiovascular disease. Am J Gastroenterol 2005;100:827-30.

6. Cher DJ. Myocardial infarction and acute cholecystitis: an application of sequence symmetry analysis. Epidemiology 2000;11:446-9.

7. Bakkaloglu H, Yanar H, Guloglu R, Taviloglu K, Tunca F, Aksoy M, et al. Ultrasound guided percutaneous cholecystostomy in high-risk patients for surgical intervention. World J Gastroenterol 2006;12:7179-82. 